\title{
A Mediator's Reflection on Family Mediation in a Recession
}

\section{Majella Foley-Friel}

\section{Abstract}

This article focusses on the personal reflections of an experienced family mediator. It looks at how, in 2014, the changed economic environment has impacted on the practice of family mediation, in particular the impact on areas such as option development. The challenge is for clients even where there is agreement between them to find workable solutions acceptable to third parties such as financial institutions.

It further looks at the principle of self-determination in a recessionary environment. Many clients are unable to make informed decisions as they await the decisions of third parties. This puts them in a legal and financial limbo which can add hugely to the stress of separation for the parties themselves and their children.

Finally, it will also refer to the positive change in attitudes to children and how this impacts on the inclusion of children in mediation.

It will conclude that the landscape of family mediation in 2014 is far more challenging than it was in 2004.

\section{Keywords}

Reflection, family mediation, mediation in recession

\section{A Mediator's Reflection on Family Mediation in a Recession}

\section{Introduction}

The reality of mediating in family mediation in 2014 is very different to mediating 10 years ago. Back in 2004 the Celtic Tiger was in full swing and everything seemed possible. The financial crisis of 2007 led to a range of severe austerity measures that are only now coming to an end. The legacy of our recession remains visible to all: significant accumulated debt, the need to maximize income opportunity at every turn, adult children living at home, often needing additional parental financial support, and of course emigration.

How then does this impact in situations where the parties, suffering under such financial burdens, separate and seek mediation to chart a new way forward? Where they have children, the mediator focuses on the fact that the parties are in mediation to sort out the practical issues so that they can start developing their own separate adult lives while co-parenting their children together. But how is 
that done against a financially bleak backdrop?

This article will look at how, in 2014, the changed environment from 2004 has impacted on both the practice of family mediation and the state supports available to separating couples, as well as the impact this has upon parenting and the children of separated couples.

\section{Mediation Practice}

Some significant principles in mediation are: empowerment, self-determination, informed decision making and techniques such as option development (Haynes, 1993), Fisher \& Ury, (1991) have contributed hugely to clients' feeling they can steer their lives in their own chosen direction. However, each of these has come under severe pressure in the current financial climate and need to be seen in the context of what constitutes a reasonable lifestyle.

\section{Self determination}

In mediation we stress that one of the primary advantages is that the parties make their own decisions as distinct from having decisions imposed upon them. It is a principle described in clause 59 of the Mediators Institute of Ireland Code of Ethics (2009) as it is in guidelines for mediators all over the world (Association of Conflict Resolution, 2010), (the International Mediators Institute, 2012). But selfdetermination may be far more illusory today than in 2004. In 2004 most clients came to the table with sufficient control over their own lives to be capable of making choices that met their needs. Today, many clients await the decisions of third parties such as banks, credit unions and the Department of Social Protection before being able to proceed and then often only within the tight confines of the consequences of these third party decisions.

Today, meeting clients whose family home is not in negative equity or arrears is a delight but significantly rarer than in 2004. Equity in the family home may give more options on how to provide two homes for the future; but even with equity, slow house sales and the limited availability of replacement mortgages for clients, often prevents realising any such equity. For those clients in negative equity, the freedom of self-determination is even more fragile as they remain trapped with no way out. Finally, where the clients have fallen into arrears, the procrastination of financial institutions is frustrating.

Even if they have negotiated a reduced mortgage repayment, it tends only to be for a limited period (e.g. 6 months) and they are then told that all the processes need to be exhausted before any long term agreement on a reduced payment can be agreed. Clients are often left waiting with no answer to their questions and knowing that any answer is not likely to be forthcoming any time soon. While the difficult decision to separate has been made, the decision around how to manage their assets and debts is dependent upon others.

\section{Option Development}

The ubiquitous story of the orange described in Fisher \& Ury (1991) encapsulates the option development tool used by mediators which empowers clients to see a range of potential options and 
choices is similarly much restricted. These are not clients burying their heads in the sand and not confronting their financial situation, but rather clients who are being proactive, trying to manage their assets and debts so that they can start developing a future for themselves and their children.

The family home and pension would have been the two significant assets for most clients. Option development around the family home has traditionally offered opportunities and possibilities around each client setting up a separate home for themselves and their children for the future. Now the family home is more of a liability; a financial liability and also an impediment to supporting families structure their lives in a more supportive environment: for example, where they might move closer to their family of origin which would be for the betterment of their own mental health and that of their children.

Often there can be many houses for sale in the area of the family home but there is no activity in the market. The option of selling the family home is academic since a sale is unlikely in these circumstances. Providing a second home is therefore unrealistic, as even renting is not affordable. An option that a lot of clients' exercise is for one of them to go back living with their now elderly parents. This client must face the reality that they will never be in a position to buy, that renting their own place is the most they can look forward to. They will have to keep paying the mortgage on the family home and are likely to be nearly seventy by the time any rescheduled mortgage is paid off.

Previously a mediator often explored one client buying out the other's interest. Where that client has invested many years of payments and a lot of work in making it the home it is, they do not want to walk away without any financial recognition of their input. Yet the best that may be possible is that their name can be removed from the mortgage so they can pursue the option of buying another home, and these are the lucky ones where there is some equity in the home. Where the house is in negative equity what interest can the party leaving the home get? It is the hopelessness they feel, knowing that it is in negative equity, wanting to move on with their lives, feeling what they invested needs to be recognized in some way and knowing that the other has not the wherewithal to do anything about it. There is often huge guilt on the part of the client staying in the family home, wishing that they could recognise the other's interest in some financial way and yet knowing they do not have the resources to do so. Where the house is in negative equity there are very few options.

Yet even keeping the family home may not be an option. Sometimes in consultations with the bank where they are trying to extend a temporary repayment agreement, the bank indicates that they do not think the clients can afford to keep the family home at all. Panic sets in for the clients. If the banks foreclose, where do the children live? Parents feel that the children are going through enough, that they just cannot allow this to happen. Pressure to increase the mortgage repayments means that other negotiated rescheduled bill repayments are not followed through. Trying to pay as much off the secured loan becomes the top priority. Sometimes the temporary arrangement has formally expired, yet there is no word on any new repayment schedule from the bank. Clients find themselves in financial limbo.

The next most significant asset for clients was the pension. Previously, exploring options around the pension could have been difficult as clients felt pensions are theirs or that it is something that will 
only be realised well into the future, so should the other not be providing for themselves at that stage? Now an extra element that arises is a concern as to whether the lump sum will still be paid when they reach retirement age or could it be that it will be taxed or reduced or abolished? Is the pension even sufficiently funded? This results in negotiations taking place in a highly stressful environment where the size of the pie is not certain. There is a lot of fear evident and consequently this makes conversations around the division of it more contentious.

Option development, which is one of the key skills in mediation, is tested yet again in looking at financial support. When charting the budget, income and expenditure often do not reconcile. Clients look to the possibility of increasing income, reducing expenditure or doing a little of both. It is always more palatable to "expand the pie" than to work with a smaller pie. However, in this economic climate opportunities for increasing income are very limited. While a growth of $3 \%$ in employment is expected this year, opportunities to earn more where someone is employed, for example through overtime, is practically non-existent. Where someone is self-employed the opportunity to increase sales in their business is minimal at best. The whole focus is on reducing expenditure. This can lead to one client attacking the other, saying: 'Well $\boldsymbol{I}$ can't cut anymore, what am I supposed to live on? You'll just have to do with less maintenance." Ill health compounds the situation where a client expresses concern that if they try and find work and come off a social welfare payment, they may not be able to get the payment again if their health fails again, so how can they take the risk?

\section{Reasonable versus actual living costs}

The guidelines on a reasonable standard of living, and reasonable living expenses, are set down in the Insolvency Service of Ireland guidelines (2013) and make for interesting reading. Although designed to be used in personal insolvencies they give an insight as to what the state believes are reasonable expenses even in the darkest of days. For an adult, of working age living alone, they estimate that the monthly expenditure on food should be $€ 250.98$ per month. Clothing and footwear should be $€ 35.43$; personal care $€ 33.06$; health $€ 31.34$; household goods to include furniture, appliances, cleaning products $€ 26.38$; household services, e.g. water charges, boiler service €27.54; communication, e.g. telephone, internet $€ 41.21$; education (books, stationery and adult education) $€ 23.72$. Childcare costs, like housing costs, are also subject to variance so these are not included in the set costs and are based on the reasonable cost of childcare and of housing.

There are comprehensive tables for adults with children in terms of allowable expenses. On reviewing these figures, it will be apparent to many mediators in working out budgets with families in mediation, that they cannot afford a lot of what is allowed in the above table. Fixed expenses such as debts take most of the money payable, mostly through direct debit, and there is absolutely no money for discretionary expenditure such as clothing or personal care. Clients increasingly rely on good health, preferring not to budget for doctors, dentists or opticians' bills. In fact, many families in mediation would be delighted if they had the amounts recommended by the Insolvency Service for those types of expenses. 


\section{Informed decisions may be costly}

Clients are always told that the best agreement is where they have all the relevant information to make informed decisions (e.g. financial information or information on their legal rights and entitlements). No one wants to look back and regret the decisions they made because of the lack of appropriate information. This does not serve the parties, their families or the mediation profession. Mediators will usually wave the red flag where they spot an information deficit. But that information can often cost, whether it is for legal expertise, financial advice or property valuations, and one of the big issues is: where do we get the money for that from? Zorza (2002) explores strategies for providing some kind of legal advice to those who cannot afford any.

The mediator's role is to facilitate the negotiation between the clients; it is not to give legal or financial advice. A challenge for a mediator in the current financial climate is to stay pure to the role and not stray into taking on the role of the solicitor or the pension expert in an effort to support the clients who are struggling to make informed decisions. This is particularly difficult where the mediator's profession of origin means they have some of the answers or they have gathered that expertise through their mediation practice.

Even at the end of the process, if agreement has been reached, formalising that agreement to give it legal effect is a cost too far. Turning to the state for help will find clients discovering that there is a twelve to eighteen month waiting list for legal aid. Some consider filling out the relevant forms themselves and going into court without legal representation as they want to move on with their lives. This increases the onus on judges where parties have no legal representation and may not have consulted a solicitor at any stage.

\section{Information and Management overload}

In addition, both for the clients and the mediator, management of a lot of disjointed and competing information becomes a crucial skill. Lang \& Taylor (2000) refer to the artistry of the mediator in the mediator's attention to detail. Mapping the client's financial landscape involves numerous tasks: clarifying what exactly is owing and to whom, tracking the different account numbers (e.g. there could be more than one credit card bill with one company); what were the original repayments agreed and what are the current repayments; what are the arrears; what bill will commence being repaid when the payment of another has been completed.

The stress associated with this predicament is enormous and words fail to capture it. Timing of salary and payments and management of this timing is an increasing worry. Will my salary make it into my bank account in time for the direct debits to be met? Direct debits all have to be paid so what will we live on until the next pay day as the account is now empty? Will there be a problem in the payment process, (witness recent issues with Eircom telling customers that direct debits had been taken when they had not and now customers are facing unforeseen huge cumulative bills). Will the bank double charge a debit Visa payment resulting in an overdraft? In 2004 banks would have allowed customers additional discretion. In 2014 there is very little discretion from the banks, even when the problems are being caused by them. 


\section{Reduction in state support}

Two further developments this year have compounded the financial quagmire for clients who are separating, particularly where they have children: first is the One Parent Family Payment; and second is the One Parent Family Tax Credit.

The One Parent Family Payment was amended in 2013 as part of the budget austerity measures. Any new application will result in it not being possible to claim a child as a dependent once they pass the age of 7 . How a child of such an age is not a dependent is astonishing! It is clear currently that children in their twenties are dependent on their parents because of the length of time they now spend in $3^{\text {rd }} \& 4^{\text {th }}$ level education. How then could a child of (for example) 9 not qualify as a dependent? How does this measure support families? What message is the state giving with respect to caring for children?

The Single Person Child Carer Credit: Now only the "primary carer" can avail of what used to be called the One Parent Family Tax Credit. This gives rise to two fundamental difficulties. Firstly, words have the potential to be loaded weapons, and although words to legislators and bureaucrats may be simply references to allocated resources, any family mediator can tell you that the use of words such as "primary" convey a clear and often provocative message. A benefit of mediation is that language is sensitively used (e.g. words such as custody and access are not part its repertoire where custody connotes one parent is parenting and the other is visiting). A very positive aspect of mediation is that the focus and language is inclusive and empowering, (for example, how are you going to co parent your children living in two separate homes, what kind of a plan needs to be put in place?). The perception of the word "primary" is that one parent is elevated above the other and it is not at all conducive to cooperative parenting where children are central to both parents, irrespective of the amount of time they get to spend with them.

Secondly, we all know how difficult it is for families in Ireland to survive this recession, so it follows it is even more difficult to support two homes in this climate. Families who were in receipt of this tax credit find that their disposable income is again reduced with the stroke of a pen. How do they make up this deficit? The introduction of this cut has had a hugely negative impact on families already struggling financially, and who are also trying to navigate their way through separation with all the emotional as well as financial burdens. Blunt instruments such as the above are steps in the wrong direction.

\section{It is not all about the money - what of the impact on children?}

So far the focus of this article has been very much on the financial difficulties that arose from the recession and the differences between 2004 and 2014. We have looked at what parents are trying to make happen in a very difficult situation. But there is more to life than just finances and that is particularly so for children innocently caught up in events not of their making. How are children affected, aside from the obvious severe financial stress that their parents are under? How else does it impact on children? 
One impact is the ability of the client to have realistic opportunities to actually spend time with their children and to continue to nurture the parent/child bond and the attachment ties which are essential for children's development into adulthood. Parents who live with elderly parents for example might live quite some distance away; the cost of transportation impacts on the frequency with which they can see their children, fueling guilt in one and exhaustion in the other as they try to manage the situation and care for the children with little or no break.

Where clients had to move back to live with elderly parents, they are often unable to have their children stay over in their family of origin's home for any number of reasons. Their parents may be too old or infirm, the house may not be big enough, or maybe other siblings of the client in the home have to be considered. Putting an adult into a situation of having to ask can their children stay over is stressful and disempowering. Putting a grandparent in the position of having to say no to their child and implicitly their grandchildren is distressing. Yet again an unenviable situation for everyone and not one that any of them saw they would be in 10 years ago.

While the other parent recognises the situation is not of the other's making, it leaves them with very limited options and everyone is stressed and frustrated with the situation. Other options parents choose is where a parent moves out of the family home at weekends to allow the other parent time with the children, and they then have to find friends where they can stay over. Doing this occasionally is one thing, but doing it every weekend becomes a huge burden. Although parents recognise the importance of children having time with both parents, and they are doing their best to make it happen, the personal price is high. Developing separate adult lives in this kindof context seems remote.

While all of the above are considerable challenges there have been some real positive developments as well. In 2012, the Thirty-first Amendment of the Constitution was passed, resulting in a new Art $42 \mathrm{~A}$ in the Constitution. This is the first stand-alone constitutional recognition of the rights of all children, rights that exist independently of their parents. Children's rights are talked about more. The idea is not as alien to parents that children may not see issues exactly as parents think they do. Mediators have a more supportive societal framework to bring up the possibility of seeing children in mediation. There is a more receptive context for children participating in mediation. Equally, how a mediator conveys the offer of children participating in mediation plays a part as to whether the opportunity is availed of. As Burell, Donohue, et al., (1990) state, mediators and disputants have a joint influence on each other in their active exchange of discourse. If the mediator presents the opportunity in a confident, competent participatory way, highlighting that the clients' separation is an equally significant event in their children's lives as it is in their own lives, parents can be often very open to allowing their children share their views in mediation. Other mediators think working with the parents will provide the opportunity to gather all the necessary information to put a good parenting plan in place, and children are best protected by keeping them out of the process.

Developments too over the last 10 years have made us more mindful of having appropriate protocols in place to protect children. It also protects mediators as professionals (e.g. having a window in the door of the room where we meet children or keeping the door ajar; ensuring the one parent waits in 
the waiting room while the mediator meet with the child; and ensuring a consent form is signed by both parents before the mediator goes ahead and meets the child).

Each of us look at the world through our own lens and experience whether we are 5,15 or 55 years of age. It is a uniqueness we each have and which is a gift to this world. When children have come into my mediation cases it always throws up something new. It may not always be easy for one or both parents to hear but it has only made the parenting agreements more robust.

\section{Conclusion}

As Shatter (1994: 5) states "since 1937 the family has been placed on a constitutional pedestal". It is the fundamental unit of society, antecedent and superior to all positive law. Such was the concern when the divorce referendum was put before the Irish people for the second time that the Government of the day promised to provide a state run mediation service to support families, so that children were safeguarded and everyone was protected as much as possible.

Legislative and executive initiatives have compounded the challenges experienced by families going through separation. Family mediation in 2014 is therefore one of little self-determination, limited options and substantially reduced state support.

What might this tell us about the impact on the social fabric of society in 20 years' time for this generation of children? How will the next generation deal with seeing one of their own parents living with elderly grandparents? What will be the impact of children's recollections of parents stressed to breaking point over losing their homes, with no idea how to pay bills or other services.

What is important to us as a nation? In Ireland our people are one of our greatest resources. Looking after our resource means providing a framework of supports for families as and when they need them, thereby providing an environment where children can grow into well-adjusted contributors to society. These are the adults of the future who will, if supported, be well educated, in good paying jobs, paying taxes, so that we can enjoy retirement. Cutting supports to those who need them now to solve one problem may well end up creating a far greater one which will need greater investment in the future in reparation. This can never be as good as preventing it happening in the first place. 


\section{References}

Bunreacht na hEireann (1937) http://www.irishstatutebook.ie/en/constitution/index.html accessed on May 5, 2014.

Burrell, N. A., W.A. Donohue, and M. Allen, (1990) The Impact of Disputants' Expectations on Mediation Testing an Interventionist Model. Human Communication Research, 17: 104-139.

Department of Social Protection http://www.welfare.ie/en/Pages/278_One-Parent-FamilyPayment.aspx, accessed on April 10, 2014.

Fisher, R., W. Ury, (1991) Getting to Yes: Negotiating without Giving In, New York, Random House. Haynes, J. (1993) Fundamentals of Family Mediation, Kent, Old Bailey Press.

Insolvency Service of Ireland Reasonable Living Expenses Guide http://www.isi.gov.ie/en/ISI/Pages/Reasonable_living_expenses, accessed on April 10, 2014.

Lang, M., A. Taylor, (2000) The Making of a Mediator: Developing Artistry in Practice, San Francisco Jossey- Bass.

Mediators Institute of Ireland Code of Ethics (2009) http://www.themii.ie/code-ofethics.jsp\#Definitions accessed on April 9, 2014.

ACR Code of Ethics (2010) http://www.acrnet.org/Page.aspx?id=1960\#Ethical Principles accessed on May 5, 2014.

IMI Code of Professional Conduct (2012) http://imimediation.org/imi-code-of-professional-conduct accessed on May 5, 2014.

Shatter, A. (1997) Family Law in the Republic of Ireland ( $4^{\text {th }}$ ed) Dublin, Tottel Publishing.

Revenue Commissioners Ireland 2014 http://www.revenue.ie/en/tax/it/credits/single-person-childcarer-credit.html accessed on April 10, 2014.

Zorza, R. (2002) Discrete Task Representation, Ethics, and the Big Picture, Family Court Review, 40: 1925.

Majella Foley-Friel, a native of Cork, graduated from UCC with a law degree before qualifying as a Barrister. Subsequently she trained as a relationship counsellor and is now an accredited Mediator with a private practice in family and workplace mediation. She also has a Masters in Mediation and Conflict Studies from UCD and an Advanced Diploma in Supervision from the University of Middlesex.

Majella has lectured and tutored in family law, mediation, domestic violence and negotiation at UL, UCD and the Law Society of Ireland among others. She is the author of a number of articles and contributions to different texts and has been a regular contributor on a number of radio and TV shows both in English and Irish. 
She has extensive experience in family mediation, having previously been the western regional manager for the state run Family Mediation Service for over nine years. In addition to her private mediation practice, she is an MII accredited trainer and works part-time as Training and Development Co-ordinator with ADAPT Domestic Abuse Services in Limerick, which provides a range of services to women survivors of domestic abuse and their children. 